\begin{tabular}{|c|c|}
\hline Title & I ridium-Catalyzed A lkene Selective Transfer Hydrogenation with 1,4-Dioxane as Hydrogen Donor \\
\hline Author(s) & Zhang, Deliang; I wai, Tomohiro; Sawamura, Masaya \\
\hline Citation & $\begin{array}{l}\text { Organic letters, 21(15), 5867-5872 } \\
\text { https://doi.org/10.1021/acs.orglett.9b01989 }\end{array}$ \\
\hline Issue Date & $2019-08-02$ \\
\hline DOC URL & http:/hdl.handle.net/2115//8899 \\
\hline Rights & $\begin{array}{l}\text { This document is the A ccepted Manuscript version of a Published Work that appeared in final form in Organic letters, } \\
\text { ๑ A merican Chemical Society after peer review and technical editing by the publisher. To access the final edited and } \\
\text { published work see https://pubs.acs.org/doi } / 10.1021 / \text { acs.orglett.9b01989 }\end{array}$ \\
\hline Type & article (author version) \\
\hline File Information & OL_1,4dioxane_v8.7_final_HUSCAP.pdf \\
\hline
\end{tabular}

Instructions for use 


\title{
Iridium-Catalyzed Alkene-Selective Transfer Hydrogenation with 1,4- Dioxane as Hydrogen Donor
}

\author{
Deliang Zhang, ${ }^{\dagger}$ Tomohiro Iwai, ${ }^{*}, \dagger$ and Masaya Sawamura $*, \dagger, *$ \\ ${ }^{\dagger}$ Department of Chemistry, Faculty of Science, Hokkaido University, Sapporo 060-0810, Japan \\ ${ }^{\ddagger}$ Institute for Chemical Reaction Design and Discovery (WPI-ICReDD), Hokkaido University, Sapporo 001-0021, Japan
}

KEYWORDS : transfer hydrogenation, 1,4-dioxane, chemoselectivity, iridium, bisphosphine

\begin{abstract}
The iridium-catalyzed transfer hydrogenation of alkenes using 1,4-dioxane as a hydrogen donor is described. The use of 1,2-bis(dicyclohexylphosphino)ethane (DCyPE), featuring bulky and highly electron-donating properties, led to high catalytic activity. A polystyrene-cross-linking bisphosphine PS-DPPBz produced a reusable heterogeneous catalyst. These homogeneous and heterogeneous protocols achieved chemoselective transfer hydrogenation of alkenes over other potentially reducible functional groups such as carbonyl, nitro, cyano and imino groups in the same molecule.
\end{abstract}

Transition metal catalyzed transfer hydrogenations are useful methods for reducing polar unsaturated bonds in organic molecules due to their high chemoselectivity without the need to use flammable hydrogen gas or complex equipment. ${ }^{1}$ Furthermore, they have potential for enantioselective catalysis. In fact, transfer hydrogenations of ketones ${ }^{2}$ and imines ${ }^{3}$ with protic $\mathrm{H}$ donor molecules such as 2-propanol and formic acid have been well established (Scheme 1a). Noyori-Ikariya-type transfer hydrogenation is a typical highly enantioselective reaction. ${ }^{4}$ In contrast, the chemoselective transfer hydrogenation of $\mathrm{C}=\mathrm{C}$ bonds in the presence of $\mathrm{C}=\mathrm{O}$ bonds and other potentially reducible functional groups such as benzylic ethers, nitriles and imines is a long-standing challenge. Although transfer hydrogenation protocols achieving appreciable but incomplete chemoselectivities in favor of $\mathrm{C}=\mathrm{C}$ bonds over ketoic $\mathrm{C}=\mathrm{O}$ bonds have been reported, ${ }^{5-7}$ the substrates were restricted to conjugated enone derivatives or the selectivities relied on careful control of the reaction conditions.

In our investigation of metal-catalyzed $\mathrm{C}\left(\mathrm{sp}^{3}\right)-\mathrm{H}$ functionalizations, ${ }^{8,9}$ we encountered a significant reduction of $\mathrm{C}=\mathrm{C}$ bonds of alkenes with 1,4-dioxane as a two-H donor in the presence of $[\mathrm{IrCl}(\mathrm{cod})]_{2}$ and some bisphosphine ligands under reasonably mild reaction conditions (bath temperature 120 $145^{\circ} \mathrm{C}, 1-4 \mathrm{~mol} \% \mathrm{Ir}$, Scheme $1 \mathrm{~b}$ ). Importantly, this transfer hydrogenation was exclusively selective toward $\mathrm{C}=\mathrm{C}$ bonds over $\mathrm{C}=\mathrm{O}$ bonds of ketones, which are the preferred reduction sites under most transfer hydrogenation conditions., ${ }^{2,3}$ Although a similar transfer hydrogenation of alkenes with 1,4dioxane catalyzed by the Wilkinson complex $\left[\mathrm{RhCl}\left(\mathrm{PPh}_{3}\right)_{3}\right]$ had been reported in 1972, the reaction conditions were harsh $\left(170{ }^{\circ} \mathrm{C}\right)$ and the substrate scope was limited to a few simple cycloalkenes. ${ }^{10}$ Therefore, we decided to investigate the interesting Ir catalysis for ligand effects, substrate scope, and chemoselectivity, having applications in organic synthesis in mind. As a result, 1,2-bis(dicyclohexylphosphino)ethane (DCyPE) was identified as an optimal ligand, which produced, in combination with $[\mathrm{IrCl}(\operatorname{cod})]_{2}$, a catalyst that promoted the highly chemoselective transfer hydrogenation of conjugated polar alkenes and isolated non-polar alkenes in the presence of ketones or other potentially reducible functional groups. To date, a broadly useful and versatile metal-catalyzed protocol that enables selective transfer hydrogenation of isolated nonpolar alkenes in the presence of ketones has not been reported. Although Huang and co-workers recently realized a similar transformation through the utilization of ethanol as a hydrogen donor catalyzed by an Ir-NCP catalyst, only two isolated nonpolar alkenes were used and chemoselectivity was not totally controlled. $^{11}$

Scheme 1. Catalytic Transfer Hydrogenations

(a) $C=X(X=0, N R)$ reduction with 2-propanol

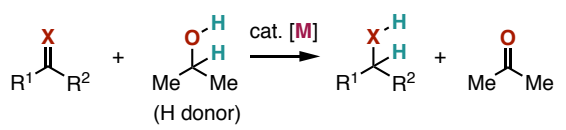

(b) $\mathrm{C}=\mathrm{C}$ reduction with 1,4-dioxane (This work)

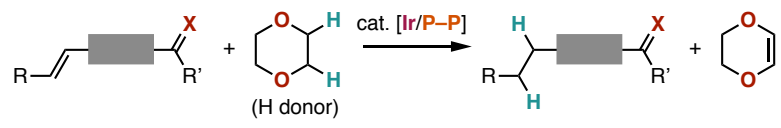

Specifically, stirring and heating of a solution of cyclic ketone $1 \mathrm{a}(1.1 \mathrm{~g}, 8.0 \mathrm{mmol})$ bearing a tert-alkyl-substituted terminal alkene moiety, $[\mathrm{IrCl}(\mathrm{cod})]_{2}(26.8 \mathrm{mg}, 0.04 \mathrm{mmol}, 1$ $\mathrm{mol} \% \mathrm{Ir}$ ), and DCyPE (33.8 $\mathrm{mg}, 0.08 \mathrm{mmol}, 1 \mathrm{~mol} \%$ ) in refluxing 1,4-dioxane $\left(10 \mathrm{~mL}\right.$ ) (bath temperature $\left.120{ }^{\circ} \mathrm{C}\right)$ under argon atmosphere over $4 \mathrm{~h}$ led to complete conversion of the starting material and afforded the corresponding saturated ketone (2a) in 97\% isolated yield (eq 1). Notably, no other reduction products 3a and $4 \mathbf{a}$ were produced. The protocol is operationally simple, and 1,4-dioxane serves as a good solvent for a range of organic compounds, suggesting a practical merit of this hydrogenation method. ${ }^{12,13}$ 


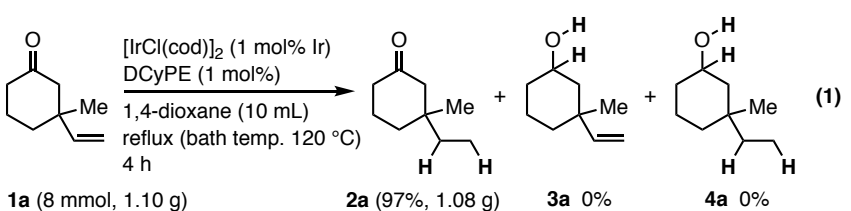

Monitoring reaction time courses by ${ }^{1} \mathrm{H}$ NMR spectroscopy clearly showed the difference between 1,4-dioxane and 2propanol as hydrogen donors (Figure 1). Thus, consistent with the above-mentioned results from the gram-scale reaction, the Ir-catalyzed transfer hydrogenation $(1 \mathrm{~mol} \% \mathrm{Ir})$ of $1 \mathrm{a}(0.2$ mmol) in 1,4-dioxane heated at $120^{\circ} \mathrm{C}$ in a sealed screw vial was exclusively chemoselective throughout the reaction (Figure 1a). On the other hand, the reaction in 2-propanol at $60^{\circ} \mathrm{C}$ ( $4 \mathrm{~mol} \% \mathrm{Ir}$ ) was only alkene-selective from the initiation of the reaction up to the half-conversion of the substrate (Figure 1b). After the brief appearance of enol 3a (40 min, 57\% conv. of 1a), overreduction product $4 \mathbf{a}$ started to form and became the major component at $90 \mathrm{~min}$. A similar trend was observed in the transfer hydrogenation of a conjugated polar alkene (see SI).
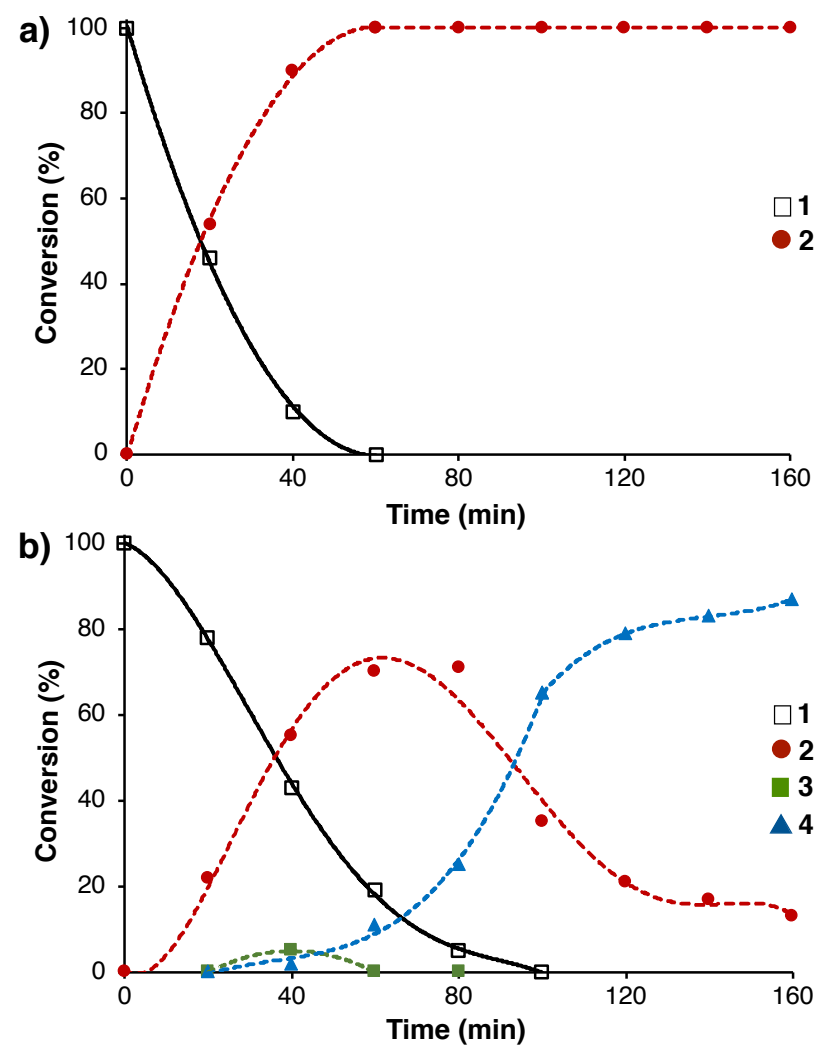

Figure 1. Time courses of transfer hydrogenation of 1a. a) 1a $(0.2$ $\mathrm{mmol}),[\mathrm{IrCl}(\mathrm{cod})]_{2}$ (1 mol\% Ir), DCyPE (1 mol\%), 1,4-dioxane $(1 \mathrm{~mL}), 120{ }^{\circ} \mathrm{C}$ (Teflon ${ }^{\circledR}$-sealed screw vial). b) 1a $(0.2 \mathrm{mmol})$, $[\mathrm{IrCl}(\mathrm{cod})]_{2}$ (4 mol\% Ir), DCyPE (4 mol\%), 2-propanol (1 mL), $60{ }^{\circ} \mathrm{C}$ (Teflon ${ }^{\circledR}$-sealed screw vial).

Other phosphines were also examined for ligand performance in the transfer hydrogenation of 4-tert-butylstyrene (1b) with 1,4-dioxane on a smaller reaction scale (1b, 0.2 mmol, $0.5 \mathrm{~mol} \% \mathrm{Ir}, \mathrm{Ir} / \mathrm{L} 1: 1,1,4$-dioxane $1 \mathrm{~mL}, 120{ }^{\circ} \mathrm{C}$ in a sealed vial, $1 \mathrm{~h}$ ). The results are summarized in Scheme 2. While monodentate phosphine ligands and large-bite-angle bisphosphine ligands such as Xantphos or DPPF were totally ineffective (see SI), 1,2-bis(diphenylphosphino)benzene (DPPBz) induced slight activity, giving $\mathbf{2 b}$ in $9 \%$ yield. The yield of $\mathbf{2 b}$ was improved to $44 \%$ with a bulkier variant (SciOPP) of DPPBz having $P$-3,5-di-tert-butylphenyl groups instead of the $P-P h$ groups. Similarly, another bulkier variant (DCyPBz) with $P$-Cy groups also gave an increased product yield of $26 \%$. Changing the 1,2-phenylene backbone of $\mathrm{DCyPBz}$ to the 3,4-thiophene-diyl backbone (DCyPT) caused a significant increase of the yield (45\%). This may be attributed to the higher electron-donating ability of the 3,4-thiophendiyl than the phenylene group.

Similar trends were observed in the examination of bisphosphine ligands with saturated carbon backbones. Namely, while a small-bite-angle ligand (DPPM) with $P$-Ph groups did not induce the reaction, changing the $P$-Ph groups to $P$-Cy groups (DCyPM) gave a highly active catalyst, leading to $89 \%$ yield. Analogously, the replacement of the $P$-Ph groups of 1,2bis(diphenylphosphino)ethane (DPPE) with $P$-Cy groups led to a dramatic increase in the product yield (from $5 \%$ to $99 \%$ ), while the effect of the change to $P$-Et groups was only marginal (12\% yield). Overall, the reactivity of the transfer hydrogenation was enhanced by steric bulk and more electrondonating ligands.

\section{Scheme 2. Ligand Effect on Transfer Hydrogenation}

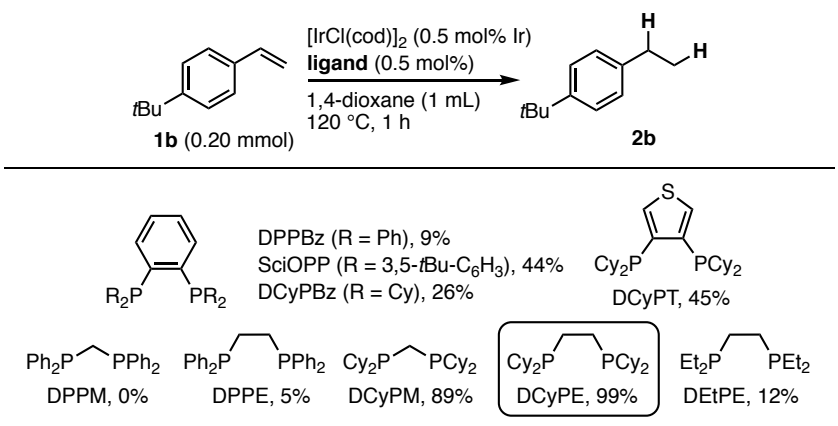

Reaction conditions: 1b $(0.2 \mathrm{mmol}),[\mathrm{IrCl}(\mathrm{cod})]_{2}(0.5 \mathrm{~mol} \% \mathrm{Ir})$, DCyPE $(0.5 \mathrm{~mol} \%)$, 1,4-dioxane $(1 \mathrm{~mL}), 120{ }^{\circ} \mathrm{C}$ (Teflon ${ }^{\circledR}$-sealed screw vial), $1 \mathrm{~h}$. Yield was determined by ${ }^{1} \mathrm{H}$ NMR analysis of the crude product.

With the optimized reaction conditions in hand, we then explored the transfer hydrogenation of various simple alkenes (Scheme 3). Styrene derivatives (1b-j) underwent transfer hydrogenation smoothly. In general, substrates with an electron-donating substituent at the para position of the aromatic ring were more reactive and required lower reaction temperature $\left(120{ }^{\circ} \mathrm{C}\right)$ and catalyst loading ( $1 \mathrm{~mol} \%$ Ir). Remarkably, the benzyloxy group in 1c and the nitro group in $\mathbf{1 f}$ remained untouched. Substrates bearing either exocyclic $\mathrm{C}=\mathrm{C}$ bonds (1h) or cyclic olefinic bonds (1j) were hydrogenated in high yields. The protocol was also applicable to various aliphatic alkenes including not only monosubstituted or 1,1disubstituted terminal alkenes $(\mathbf{1} \mathbf{k}, \mathbf{m}, \mathbf{n})$ but also disubstituted or trisubstituted internal alkenes $(\mathbf{1 1}, \mathbf{0}, \mathbf{p})$, while tetrasubstituted alkenes such as 2,3-dimethyl-1H-indene and tetraphenylethylene did not participated in the present transfer hydrogenation even at higher reaction temperature $\left(140{ }^{\circ} \mathrm{C}\right)$. Notably, the allyl and benzyl ether moieties of 10 were innocent of hydrogenolysis reactivity. 
Scheme 3. Scope of Simple Alkenes

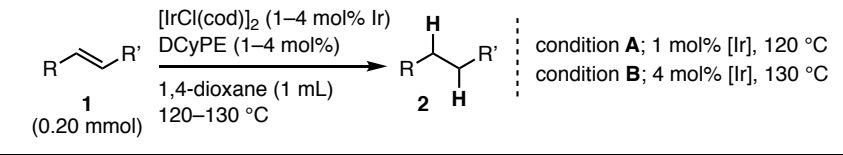

aryl alkenes

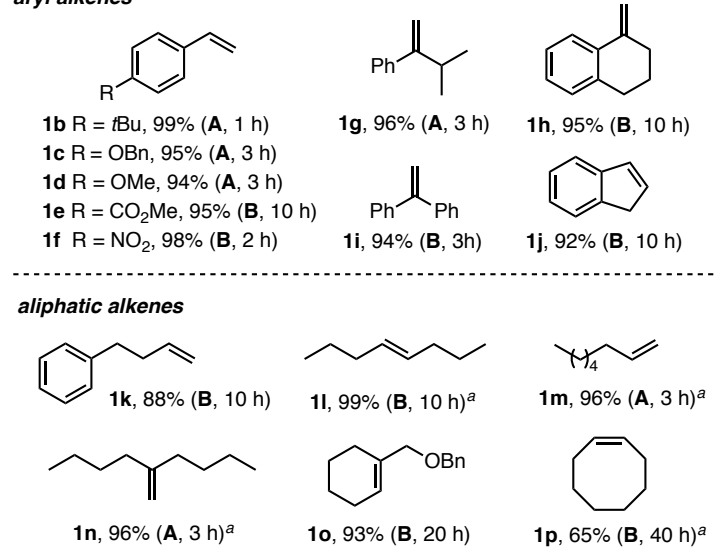

Reaction condition A: 1 (0.2 mmol), [IrCl(cod) $]_{2}(1 \mathrm{~mol} \% \mathrm{Ir})$, DCyPE $(1 \mathrm{~mol} \%), 1,4$-dioxane $(1 \mathrm{~mL}), 120^{\circ} \mathrm{C}$ (Teflon ${ }^{\mathbb{B}}$-sealed screw vial). Reaction condition B: $1(0.2 \mathrm{mmol}),[\mathrm{IrCl}(\mathrm{cod})]_{2}(4$ mol\% Ir), DCyPE (4 mol\%), 1,4-dioxane $(1 \mathrm{~mL}), 130^{\circ} \mathrm{C}$ (Teflon ${ }^{\mathbb{B}}$-sealed screw vial). Yields of isolated product are shown. ${ }^{a}$ Yield was determined by ${ }^{1} \mathrm{H}$ NMR analysis of the crude product.

Alkynes also underwent the transfer hydrogenation using 1,4-dioxane as $\mathrm{H}$ donor with the same catalyst. Diphenylacetylene (5) was converted to 1,2-diphenylethane (6) through double transfer hydrogenation with $4 \mathrm{~mol} \%$ Ir loading at $140{ }^{\circ} \mathrm{C}$ over $20 \mathrm{~h}$ (eq 2), while the reaction of a terminal alkyne phenylacetylene suffered from significant oligomerization under the same reaction condition.

$$
\mathbf{P h}=-\mathrm{Ph} \underset{(0.20 \mathrm{mmol})}{\stackrel{\operatorname{DCyPE}(4 \mathrm{~mol} \%)}{1,4-\text { dioxane }(1 \mathrm{~mL})}} \underset{140^{\circ} \mathrm{C}, 20 \mathrm{~h}}{\mathrm{IrCl}(\mathrm{cod})]_{2}(4 \mathrm{~mol} \% \mathrm{Ir})}
$$

The chemoselectivity of this protocol toward $\mathrm{C}=\mathrm{C}$ hydrogenation was further examined with various functionalized alkenes as showcased in Scheme 4. Benzylideneacetone derivatives $(\mathbf{1 q}-\mathbf{w})$ bearing electron-donating or withdrawing groups on the aromatic ring were suitable substrates, providing the desired products with excellent yields and exclusive chemoselectivity. The protocol was applicable to the sulfidefunctionalized enone (1v), although a higher reaction temperature and longer reaction time were required. The aromatic ring could be polycyclic (1x, 1y) or $S$-heterocyclic (1ab). An aliphatic conjugated enone (1z) and chalcone (1aa) also underwent clean $\mathrm{C}=\mathrm{C}$ reduction. The protocol was also applicable to more sterically hindered enones such as 4,4-dimethyl-2cyclohexene-1-one (1ac) and (E)-4-phenylpent-3-en-2-one (1ad). Conjugated enoates (1ae, 1af) and an enamide (1ag) were also reduced at the $\mathrm{C}=\mathrm{C}$ bond.

Scheme 4 also shows the scope of functionalized non-polar alkenes. Terminal alkenes bearing an acetophenone or cyclohexanone (1ah-al) underwent site-selective reduction at the alkene moiety. Tolerance toward nitro and cyano groups was confirmed in the reaction of the biphenyl derivatives $1 \mathbf{a m}$ and 1an. The $\mathrm{C}=\mathrm{N}$ bond in $N$-sulfonyl ketimine 1 ao also remained untouched. The chemoselective transfer hydrogenation of an estrone derivative (1ap) highlights the synthetic utility of this hydrogenation method.

\section{Scheme 4. Alkene-Selective Transfer Hydrogenation}

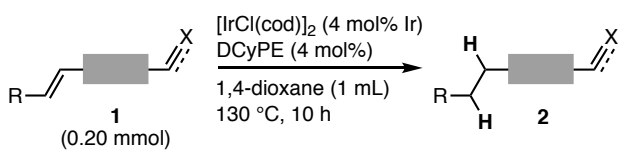

conjugated polar alkenes
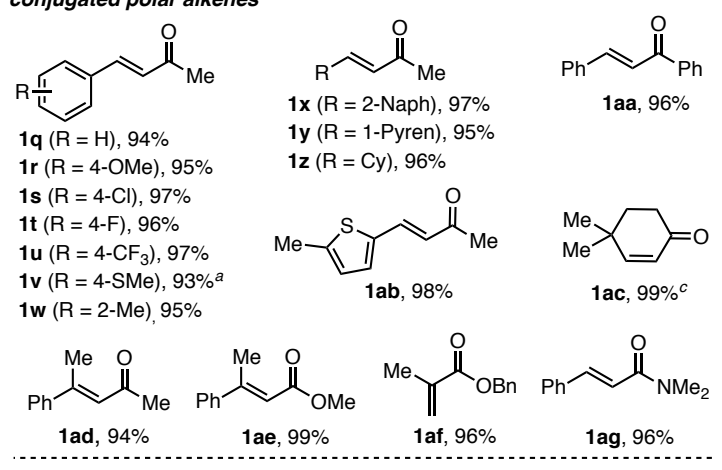

functionalized non-polar alkenes

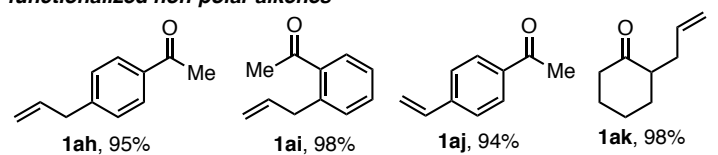

1ah, $95 \% \quad$ 1ai, $98 \%$

1aj, $94 \%$

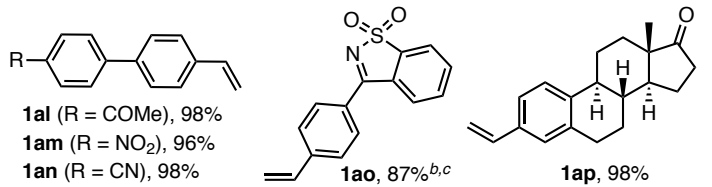

Reaction conditions: 1 (0.2 mmol), $[\operatorname{IrCl}(\operatorname{cod})]_{2}$ (4 mol\% Ir), DCyPE $(4 \mathrm{~mol} \%), 1,4$-dioxane $(1 \mathrm{~mL}), 130{ }^{\circ} \mathrm{C}$ (Teflon ${ }^{\circledR}$-sealed screw vial), $10 \mathrm{~h}$. Yields shown are of isolated product. ${ }^{a}$ Run at $145{ }^{\circ} \mathrm{C}$ (glass pressure tube) over $48 \mathrm{~h} .{ }^{b}$ Run in 1,4-dioxane $(1.5$ $\mathrm{mL}$ ) at $145{ }^{\circ} \mathrm{C}$ (glass pressure tube) over $48 \mathrm{~h} .{ }^{c}$ Yield was determined by ${ }^{1} \mathrm{H}$ NMR analysis of the crude product.

To gain insight into the mechanism, the effects of deuterated 1,4-dioxane were investigated. Thus, the Ir-catalyzed transfer hydrogenation of $1 \mathrm{c}(0.1 \mathrm{mmol}, 4 \mathrm{~mol} \% \mathrm{Ir})$ in a mixed solvent system composed of 1,4-dioxane $(0.3 \mathrm{~mL})$ and $1,4-$ dioxane- $d_{8}(0.3 \mathrm{~mL})$ conducted at $130{ }^{\circ} \mathrm{C}$ proceeded at a much reduced rate than in the single component non-deuterated $1,4-$ dioxane, resulting in the formation of $2 \mathrm{c}$ in only $48 \%$ yield after $24 \mathrm{~h}$ with no $D$-incorporation in the product (eq 3 ). When the reaction was performed in the single component deuterated solvent 1,4 -dioxane- $d_{8}(0.3 \mathrm{~mL})$ under the same reaction conditions, the deuterated product was obtained in $13 \%$ yield with $82 \% D$-incorporation in the methylene group and $118 \% D$ incorporation in the methyl group (eq 4). These results prove that 1,4-dioxane is the hydrogen donor. The unusually high kinetic isotope effect suggests that dissociations of two different $\mathrm{C}\left(\mathrm{sp}^{3}\right)-\mathrm{H}$ bonds in 1,4-dioxane, one at $\mathrm{C}(2)$ and the other at $\mathrm{C}(3)$, doubly affect the rate of the catalysis. Namely, it is suggested that both $\mathrm{C}(2)-\mathrm{H}$ oxidative addition to an Ir center forming an Ir-monohydride species and the subsequent $\beta$ hydride elimination giving an $\operatorname{Ir}(\mathrm{III})$ dihydride species may contribute to the total kinetics of the catalysis. Furthermore, the unequal $D$-incorporation at $\mathrm{C}(\alpha)$ and $\mathrm{C}(\beta)$ of $2 \mathbf{c}$ is suggestive of the occurrence of $\beta$-hydride elimination of a benzylic alkyliridium intermediate. 


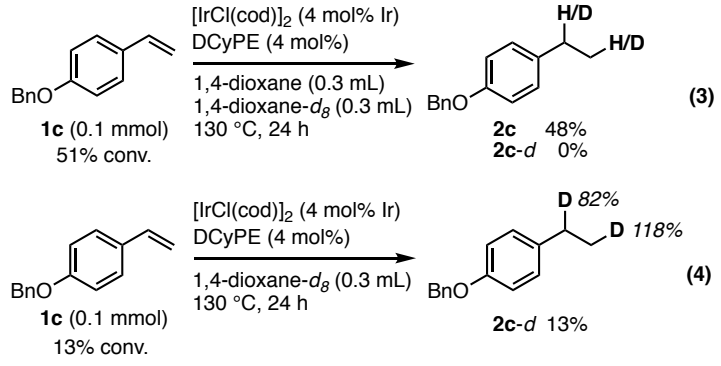

On the basis of the above experimental results, a catalytic reaction pathway for the transfer hydrogenation of an alkene with 1,4-dioxane can be proposed as outlined in Scheme 5. Oxidative addition of a $\mathrm{C}\left(\mathrm{sp}^{3}\right)-\mathrm{H}$ bond in 1,4-dioxane to the $\operatorname{Ir}(\mathrm{I})$ center in A yields $\operatorname{Ir}(\mathrm{III})$ monohydride B. Subsequent $\beta$ hydride elimination generates $\operatorname{Ir}($ III) dihydride species $\mathbf{C}$, which, depending on the nature of the phosphine ligand bound to the Ir atom, should be in equilibrium with hydride-bridged dimeric iridium complex $\mathbf{C}$-dimer as an off cycle species. ${ }^{14}$ The alkene coordinates to $\mathbf{C}$ to form $\mathbf{D}$. This is followed by insertion of the alkene to the Ir-H bond of $\mathbf{D}$ to form Ir-alkyl complex $\mathbf{E}$, which undergoes reductive elimination to produce the 1,2-hydrogenation product $\mathbf{2}$ with regeneration of $\mathbf{A} .^{15,16}$

\section{Scheme 5. Proposed Reaction Pathway}

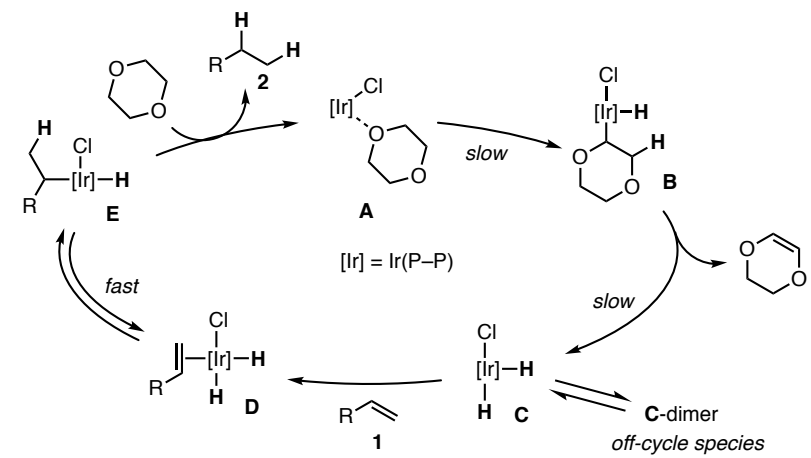

According to this $\mathrm{C}\left(\mathrm{sp}^{3}\right)-\mathrm{H}$ activation triggered reaction pathway, the ligand electronic effect favoring the electron-rich nature may be due to the promotion of oxidative addition of the $\mathrm{C}\left(\mathrm{sp}^{3}\right)-\mathrm{H}$ bond of 1,4-dioxane in $\mathbf{A}$ to form $\mathbf{B}$, while the favorable effect of the sterically hindered bisphosphine ligands can be ascribed to an inhibitory effect for the dimerization of C.

This mechanistic consideration prompted us to use a polystyrene-cross-linking bisphosphine PS-DPPBz ${ }^{17,18}$ as an effective ligand for a reusable heterogeneous catalyst system (Scheme 6), as its excellent ligand performance has been demonstrated for some heterogeneous transition metal catalysis. The characteristic ligand property was due to spatial isolation of the bisphosphine unit in the polymer matrix, inhibiting the formation of a bischelated metal complex or a dimer of a monochelate complex (c.f. C-dimer in Scheme 5). Specifically, the hydrogenation of $1 \mathrm{a}(1 \mathrm{mmol})$ with 1,4 -dioxane $(0.33 \mathrm{M})$ at $145{ }^{\circ} \mathrm{C}$ in the presence of $[\mathrm{IrCl}(\mathrm{cod})]_{2}$ and PS-DPPBz (Ir/L $1: 1,1 \mathrm{~mol} \% \mathrm{Ir})$ was complete at $4 \mathrm{~h}\left(98 \%\right.$ yield by ${ }^{1} \mathrm{H} \mathrm{NMR}$ analysis) (Scheme $6,1^{\text {st }}$ run). The [Ir-(PS-DPPBz)] catalyst in a form of orange-colored beads could be reused until the third reaction cycle without a significant reduction of the product yield under the identical reaction conditions (4-5 h), while the catalytic efficiency was gradually reduced after the third cycle.
Scheme 6. Heterogeneous Transfer Hydrogenation of 1a with 1,4-Dioxane and the [Ir-(PS-DPPBz)] Catalyst System
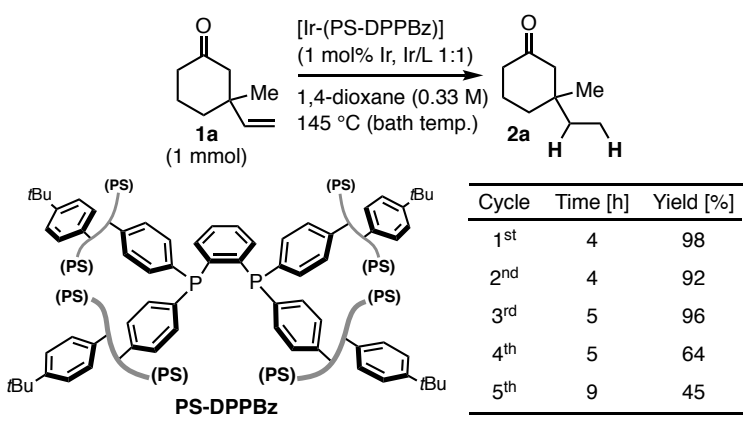

Reaction conditions: 1a $(1 \mathrm{mmol}),[\mathrm{IrCl}(\mathrm{cod})]_{2}(0.005 \mathrm{mmol}, 1$ $\mathrm{mol} \%$ Ir $)$, PS-DPPBz (0.1 mmol $/ \mathrm{g}, 0.01 \mathrm{mmol}, 1 \mathrm{~mol} \%), 1,4-$ dioxane $(0.33 \mathrm{M}), 145{ }^{\circ} \mathrm{C}$ (glass pressure tube). Yield was determined by ${ }^{1} \mathrm{H}$ NMR analysis of crude product.

In conclusion, we have developed a new operationally simple method for the transfer hydrogenation of alkenes with 1,4-dioxane as a hydrogen donor. The commercially available bulky and electron-rich ligand DCyPE was identified to be a particularly high-performing ligand. A polystyrene-crosslinking bisphosphine PS-DPPBz produced a reusable heterogeneous catalyst. In contrast to the transition metal catalyzed transfer hydrogenation with protic hydrogen donor reagents or solvents, the present hydrogenation protocol is alkene selective in the presence of polar unsaturated bonds such as $\mathrm{C}=\mathrm{O}$, $\mathrm{C}=\mathrm{N}$ and $\mathrm{C} \equiv \mathrm{N}$ bonds. Mechanistically, this hydrogenation is triggered by oxidative addition of a 1,4-dioxane $\mathrm{C}\left(\mathrm{sp}^{3}\right)-\mathrm{H}$ bond. We anticipate this method to find widespread application in organic synthesis. Studies toward developing an asymmetric version of this transformation are underway.

\section{ASSOCIATED CONTENT}

\section{Supporting Information}

The Supporting Information is available free of charge on the

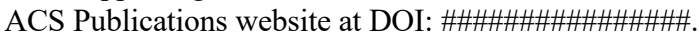

Experimental procedures and the characterization of all new compound (PDF)

\section{AUTHOR INFORMATION}

\section{Corresponding Author}

*E-mail: iwai-t@sci.hokudai.ac.jp

*E-mail: sawamura@sci.hokudai.ac.jp

\section{Notes}

The authors declare no competing financial interest.

\section{ACKNOWLEDGMENT}

This work was supported by JSPS KAKENHI Grant Number JP17H04877 in Young Scientists (A) to T.I., and by JSPS KAKENHI Grant Number JP15H05801 in Precisely Designed Catalysts with Customized Scaffolding, and JSPS KAKENHI Grant Number JP18H03906 in Grant-in-Aid for Scientific Research (A) to M.S. D.Z. thanks JSPS for a scholarship support.

\section{REFERENCES}


(1) For selected reviews on transfer hydrogenation reactions, see: (a) Brieger, G.; Nestrick, T. J. Catalytic Transfer Hydrogenation. Chem. Rev. 1974, 74, 567-580. (b) Johnstone, R. A. W.; Wilby, A. H.; Entwistle, I. D. Heterogeneous Catalytic Transfer Hydrogenation and its Relation to Other Methods for Reduction of Organic Compounds. Chem. Rev. 1985, 85, 129-170. (c) Zassinovich, G.; Mestroni, G.; Gladiali, S. Asymmetric Hydrogen Transfer Reactions Promoted by Homogeneous Transition Metal Catalysts. Chem. Rev. 1992, 92, 1051-1069. (d) Fujita, K.; Yamaguchi, R. Cp*Ir Complex-Catalyzed Hydrogen Transfer Reactions Directed towards Environmentally Benign Organic Synthesis. Synlett 2005, 560-571. (e) Dobereiner, G. E.; Crabtree, R. H. Dehydrogenation as a Substrate-Activating Strategy in Homogeneous Transition-Metal Catalysis. Chem. Rev. 2010, 110, 681-703. (f) Wang, D.; Astruc, D. The Golden Age of Transfer Hydrogenation. Chem. Rev. 2015, 115, 6621-6686. (g) Werkmeister, S.; Neumann, J.; Junge, K.; Beller, M. Pincer-Type Complexes for Catalytic (De)Hydrogenation and Transfer (De)Hydrogenation Reactions: Recent Progress. Chem. Eur. J. 2015, 21, 12226-12250.

(2) For selected references on transfer hydrogenation of ketones, see: (a) Reetz, M. T.; Li, X. An Efficient Catalyst System for the Asymmetric Transfer Hydrogenation of Ketones: Remarkably Broad Substrate Scope. J. Am. Chem. Soc. 2006, 128, 1044-1045. (b) Clarke, Z. E.; Maragh, P. T.; Dasgupta, T. P.; Gusev, D. G.; Lough, A. J.; Abdur-Rashid, K. A Family of Active Iridium Catalysts for Transfer Hydrogenation of Ketones. Organometallics 2006, 25, 4113-4117. (c) Sonnenberg, J. F.; Coombs, N.; Dube, P. A.; Morris, R. H. Iron Nanoparticles Catalyzing the Asymmetric Transfer Hydrogenation of Ketones. J. Am. Chem. Soc. 2012, 134, 5893-5899. (d) Johnson, T. C.; Totty, W. G.; Wills, M. Application of Ruthenium Complexes of Trizole-Containing Tridentate Ligands to Asymmetric Transfer Hydrogenation of Ketones. Org. Lett. 2012, 14, 5230-5233. (e) Zuo, W.; Lough, A. J.; Li, Y. F.; Morris, R. H. Amine(imine)diphosphine Iron Catalyst for Asymmetric Transfer Hydrogenation of Ketones and Imines. Science 2013, 342, 1080-1083. (f) Touge, T.; Nara, H.; Fujiwhara, M.; Kayaki, Y.; Ikariya, T. Efficient Access to Chiral Benzhydrols via Asymmetric Transfer Hydrogenation of Unsymmetrical Benzophenones with Bifunctional Oxo-Tether Ruthenium Catalysts. $J$. Am. Chem. Soc. 2016, 138, 10084-10087.

(3) For selected references on transfer hydrogenation of imines, see: (a) Uematsu, N.; Fujii, A.; Hashiguchi, S.; Ikariya, T.; Noyori, R. Asymmetric Transfer Hydrogenation of Imines. J. Am. Chem. Soc. 1996, 118, 4916-4917. (b) Gnanamgari, D.; Moores, A.; Rajaseelan, E.; Grabtree, R. H. Transfer Hydrogenation of Imines and Alkenes and Direct Reduction Amination of Aldehydes Catalyzed by TriazoleDerived Iridium(I) Carbene Complexes. Organometallics 2007, 26, 1226-1230. (c) Wang, C.; Pettman, A.; Bacsa, J.; Xiao, J. A Versatile Catalyst for Reductive Amination by Transfer Hydrogenation. Angew. Chem., Int. Ed. 2010, 49, 7548-7552. (d) Li, S.; Li, G.; Meng, W.; Du, H. A Frustrated Lewis Pair Catalyzed Asymmetric Transfer Hydrogenation of Imines Using Ammonia Borane. J. Am. Chem. Soc. 2016, 138, 12956-12962.

(4) (a) Hashiguchi, S.; Fujii, A.; Takehara, J.; Ikariya, T.; Noyori, R. Asymmetric Transfer Hydrogenation of Aromatic Ketones Catalyzed by Chiral Ruthenium(II) Complexes. J. Am. Chem. Soc. 1995, 117, 7562-7563. (b) Noyori, R.; Hashiguchi, S. Asymmetric Transfer Hydrogenation Catalyzed by Chiral Ruthenium Complexes. Acc. Chem. Res. 1997, 30, 97-102. (c) Noyori, R. Asymmetric Catalysis: Science and Opportunities. Angew. Chem., Int. Ed. 2002, 41, 20082022. (d) Ikariya, T.; Murata, K.; Noyori, R. Bifunctional Transition Metal-Based Molecular Catalysts for Asymmetric Syntheses. Org. Biomol. Chem. 2006, 4, 393-406.

(5) For alcohol as a hydrogen donor, see: (a) Sasson, Y.; Blum, J. Dichlorotris(triphenylphosphine)ruthenium-Catalyzed Hydrogen Transfer from Alcohols to Saturated and $\alpha, \beta$-Unsaturated Ketones. $J$. Org. Chem. 1975, 40, 1887-1896. (b) Sakaguchi, S.; Yamaga, T.; Ishii, Y. Iridium-Catalyzed Transfer Hydrogenation of $\alpha, \beta$ Unsaturated and Saturated Carbonyl Compounds with 2-Propanol. $J$. Org. Chem. 2001, 66, 4710-4712. (c) Ding, B.; Zhang, Z.; Liu, Y.; Sugiya, M.; Imamoto, T.; Zhang, W. Chemoselective Transfer Hydrogenation of $\alpha, \beta$-Unsaturated Ketones Catalyzed by Pincer-Pd Complexes Using Alcohol as a Hydrogen Source. Org. Lett. 2013, 15,
3690-3693. (d) Chen, S.-J.; Lu, G.-P.; Cai, C. A Base-Controlled Chemoselective Transfer Hydrogenation of $\alpha, \beta$-Unsaturated Ketones Catalyzed by $\left[\mathrm{IrCp}^{*} \mathrm{Cl}_{2}\right]_{2}$ with 2-Propanol. RSC Adv. 2015, 5, 1320813211.

(6) For hydrosilane as a hydrogen donor, see: (a) Keinan, E.; Greenspoon, N. Highly Chemoselective Palladium-Catalyzed Conjugate Reduction of $\alpha, \beta$-Unsaturated Carbonyl Compounds with Silicon Hydrides and Zinc Chloride Cocatalyst. J. Am. Chem. Soc. 1986, 108, 7314-7325. (b) Appella, D. H.; Moritani, Y.; Shintani, R.; Ferreira, E. M.; Buchwald, S. L. Asymmetric Conjugate Reduction of $\alpha, \beta-$ Unsaturated Esters Using a Chiral Phosphine-Copper Catalyst. J. Am. Chem. Soc. 1999, 121, 9473-9474. (c) Moritani, Y.; Appella, D. H.; Jurkauskas, V.; Buchwald, S. L. Synthesis of $\beta$-Alkyl Cyclopentanones in High Enantiomeric Excess via Copper-Catalyzed Asymmetric Conjugate Reduction. J. Am. Chem. Soc. 2000, 122, 6797-6798. (d) Lipshutz, B. H.; Servesko, J. M. CuH-Catalyzed Asymmetric Conjugate Reduction of Acyclic Enones. Angew. Chem., Int. Ed. 2003, 42, 4789-4792.

(7) For formate as a hydrogen donor, see: (a) Himeda, Y.; Onozawa-Komatsuzaki, N.; Miyazawa, S.; Sugihara, H.; Hirose, T.; Kasuga, K. pH-Dependent Catalytic Activity and Chemoselectivity in Transfer Hydrogenation Catalyzed by Iridium Complex with 4,4'-Dihyroxys2,2'-bipyridine. Chem. Eur. J. 2008, 14, 11076-11081. (b) Li, X.; Li, L.; Tang, Y.; Zhong, L.; Cun, L.; Zhu, J.; Liao, J.; Deng, J. Chemoselective Conjugate Reduction of $\alpha, \beta$-Unsaturated Ketones Catalyzed by Rhodium Amido Complexes in Aqueous Media. J. Org. Chem. 2010, 75, 2981-2988.

(8) For selected reviews on metal-catalyzed $\mathrm{C}\left(\mathrm{sp}^{3}\right)-\mathrm{H}$ functionalization reactions, see: (a) Labinger, J. A.; Bercaw, J. E. Understanding and Exploiting C-H Bond Activation. Nature 2002, 417, 507-514. (b) Hartwig, J. F. Carbon-Heteroatom Bond Formation Catalysed by Organometallic Complexes. Nature 2008, 455, 314-322. (c) Lyons, T. W.; Sanford, M. S. Palladium-Catalyzed Ligand-Directed C-H Functionalization Reactions. Chem. Rev. 2010, 110, 1147-1169. (d) Shang, R.; Ilies, L.; Nakamura, E. Iron-Catalyzed C-H Bond Activation. Chem. Rev. 2017, 117, 9086-9139. (e) He, J.; Wasa, M.; Chan, K. S. L.; Shao, Q.; Yu, J.-Q. Palladium-Catalyzed Transformation of Alkyl C-H Bonds. Chem. Rev. 2017, 117, 8754-8786. (f) Chu, C. K.; Rovis, T. Complementary Strategies for Directed C $\left(\mathrm{sp}^{3}\right)-\mathrm{H}$ Functionalization: A Comparison of Transition-Metal-Catalyzed Activation, Hydrogen Atom Transfer, and Carbene/Nitrene Transfer. Angew. Chem., Int. Ed. 2018, 57, 62-101.

(9) For our work on $\mathrm{C}\left(\mathrm{sp}^{3}\right)-\mathrm{H}$ functionalization, see: (a) Kawamorita, S.; Miyazaki, T.; Iwai, T.; Ohmiya, H.; Sawamura, M. RhCatalyzed Borylation of N-Adjacent $\mathrm{C}\left(\mathrm{sp}^{3}\right)-\mathrm{H}$ Bonds with a SilicaSupported Triaryphosphine Ligand. J. Am. Chem. Soc. 2012, 134, 12924-12927. (b) Kawamorita, S.; Murakami, R.; Iwai, T.; Sawamura, M. Synthesis of Primary and Secondary Alkylboronates through SiteSelective $\mathrm{C}\left(\mathrm{sp}^{3}\right)-\mathrm{H}$ Activation with Silica-Supported Monophosphine-Ir Catalysts. J. Am. Chem. Soc. 2013, 135, 2947-2950. (c) Reyes, R. L.; Harada, T.; Taniguchi, T.; Monde, K.; Iwai, T.; Sawamura, M. Enantioselective Rh- or Ir-Catalyzed Directed C( $\left(\mathrm{sp}^{3}\right)$ H Borylation with Phosphoramidite Chiral Ligands. Chem. Lett. 2017, 46, 1747-1750. (d) Murakami, R.; Sano, K.; Iwai, T.; Taniguchi, T.; Monde, K.; Sawamura, M. Palladium-Catalyzed Asymmetric C( $\left(\mathrm{sp}^{3}\right)-$ H Allylation of 2-Alkylpyridines. Angew. Chem., Int. Ed. 2018, 57, 9465-9469. (e) Reyes, R. L.; Iwai, T.; Maeda, S.; Sawamura, M. Iridium-Catalyzed Asymmetric Borylation of Unactivated Methylene C( $\left(\mathrm{sp}^{3}\right)-$ H Bonds. J. Am. Chem. Soc. 2019, 141, 6817-6821.

(10) (a) Nishiguchi, T.; Tachi, K.; Fukuzumi, K. Hydrogen Transfer from Dioxane to an Olefin Catalyzed by Chlorotris(triphenylphosphine)rhodium(I). J. Am. Chem. Soc. 1972, 94, 8916-8917. (b) Nishiguchi, T.; Fukuzumi, K. Transfer-Hydrogenation and Transfer-Hydrogenolysis. III. Hydrogen Transfer from Dioxane to Olefins Catalyzed by Chlorotris(triphenylphosphine)rhodium(I). $J$. Am. Chem. Soc. 1974, 96, 1893-1897.

(11) Wang, Y.; Huang, Z.; Leng, X.; Zhu, H.; Liu, G.; Huang, Z. Transfer Hydrogenation of Alkenes Using Ethanol Catalyzed by a NCP Pincer Iridium Complex: Scope and Mechanism. J. Am. Chem. Soc. 2018, 140, 4417-4429. 
(12) THF also served as a hydrogen donor albeit with much lower reaction efficacy. A linear ether 1,2-diethoxyethane induced no transfer hydrogenation (See SI). Ohmura and Suginome described the occurrence of transfer hydrogenation of alkenes and alkynes from THF or octane solvents as side reactions of Ir-catalyzed reactions. (a) Torigoe, T.; Ohmura, T.; Suginome, M. Iridium-Catalyzed Intramolecular Methoxy $\mathrm{C}-\mathrm{H}$ Addition to Carbon-Carbon Triple Bonds: Direct Synthesis of 3-Substituted Benzofurans from oMethoxyphenylalkynes. Chem. Eur. J. 2016, 22, 10415-10419. (b) Torigoe, T.; Ohmura, T.; Suginome, M. Asymmetric Cycloisomerization of $o$-Alkenyl- $N$-Methylanilines to Indolines by Iridium-Catalyzed $\mathrm{C}\left(\mathrm{sp}^{3}\right)-\mathrm{H}$ Addition to Carbon-Carbon Double Bonds. Angew. Chem., Int. Ed. 2017, 56, 14272-14276.

(13) Formation of 1,4-dioxa-2-cyclohexene was confirmed by ${ }^{1} \mathrm{H}$ NMR analysis of the reaction mixture.

(14) Tani, K.; Iseki, A.; Yamagata, T. Efficient Transfer Hydrogenation of Alkynes and Alkenes with Methanol Catalysed by Hydrido(methoxo)iridium(III) Complexes. Chem. Commun. 1999, 18211822.

(15) In contrast, a reaction pathway for the transfer hydrogenation with 2-propanol would involve the generation of alchohol-bound Irhydride species $(\mathbf{F})$, which may offer a route for outer-sphere concerted transfer of proton and hydride. This would be responsible for the reactivity of the $\mathrm{C}=\mathrm{O}$ bonds.

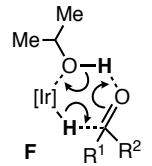

(16) Samec, J. S. M.; Bäckvall, J.-E.; Andersson, P. G.; Brandt, P. Mechanistic Aspects of Transition Metal-Catalyzed Hydrogen Transfer Reactions. Chem. Soc. Rev. 2006, 35, 237-248.

(17) (a) Iwai, T.; Harada, T.; Shimada, H.; Asano, K.; Sawamura, M. A Polystyrene-Cross-Linking Bisphosphine: Controlled Metal Monochelation and Ligand-Enabled First-Row Transition Metal Catalysis. ACS Catal. 2017, 7, 1681-1692. (b) Yamazaki, Y.; Arima, N.; Iwai, T.; Sawamura, M. Heterogeneous Nickel-Catalyzed CrossCoupling between Aryl Chlorides and Alkyllithiums Using a Polystyrene-Cross-Linking Bisphosphine Ligand. Adv. Synth. Catal. 2019, 361, 2250-2254. (c) Nishizawa, A.; Takahira, T.; Yasui, K.; Fujimoto, H.; Iwai, T.; Sawamura, M.; Chatani, N.; Tobisu, M. NickelCatalyzed Decarboxylation of Aryl Carbamates for Converting Phenols into Aromatic Amines. J. Am. Chem. Soc. 2019, 141, 7261-7265.

(18) While PS-DPPBz gave $\mathbf{2 b}$ in a yield (11\%) comparable to that with the corresponding homogeneous ligand DPPBz (9\%) under the otherwise same conditions as Scheme $2\left(0.5 \mathrm{~mol} \% \mathrm{Ir}, 120{ }^{\circ} \mathrm{C}, 1 \mathrm{~h}\right)$, the polymer effect was significant at a longer reaction time $(9 \mathrm{~h}, 1$ mol\% Ir): 97\% yield with PS-DPPBz, 48\% yield with DPPBz. 


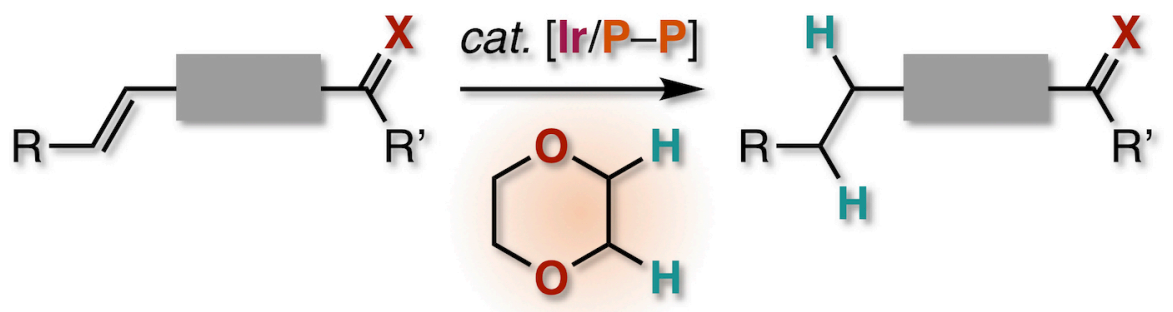

- Chemoselective $C=C$ reduction

- Broad substrate scope

- Simple operation 